\title{
Séance du 30 juin 2011
}

Etude sur les transferts de prestations et de coûts entre le secteur stationnaire et le secteur ambulatoire (hôpitaux et cabinets) - Dans le cadre de l'introduction du système SwissDRG, le Comité central de la FMH a attribué le mandat d'une étude concomitante sur les transferts de prestations et de coûts des examens et traitements entre le secteur stationnaire et le secteur ambulatoire (hôpitaux et cabinets).

ORTRA Formation professionnelle des assistantes médicales - La FMH assure jusqu'à l'automne le financement de deux cursus de formation continue pour les assistantes médicales diplômées par le biais d'une contribution spécialement inscrite au budget. Ensuite, l'Office fédéral de la formation professionnelle et de la technologie apportera son soutien à l'ORTRA Formation professionnelle des assistantes médicales.

TARMEDSuisse/Traitement de la douleur - Dans la structure tarifaire TARMED, le chapitre 29, «Traitement de la douleur», a été révisé et intégré dans la ver- sion $1.08 \mathrm{du}$ TARMED en vue de son approbation par le Conseil fédéral.

Présidence de la QUALAB - Le CC approuve la proposition d'alterner chaque année la présidence entre les partenaires contractuels au sein de la Commission suisse pour l'assurance qualité dans le laboratoire médical (QUALAB).

«Oui à la médecine de famille» - La FMH publie sa prise de position relative au contre-projet du Conseil fédéral à l'initiative populaire «Oui à la médecine de famille».

Inscriptions dans I'annuaire téléphonique - Seules les personnes physiques peuvent être inscrites sous la rubrique «Médecins» de l'annuaire téléphonique. Une exception est cependant admise en ce qui concerne la rubrique «Urgence (service $\mathrm{d}^{\prime}$ )». Etant donné que la télémédecine n'est pas spécifique au domaine des urgences, il s'agit de créer une rubrique «Télémédecine» juste en dessous de celle des urgences.

\section{Nouvel outil pédagogique:} manuel de formation au cabinet médical.

\section{Ouvrage didactique pour formateurs et assistantes médicales en formation.}

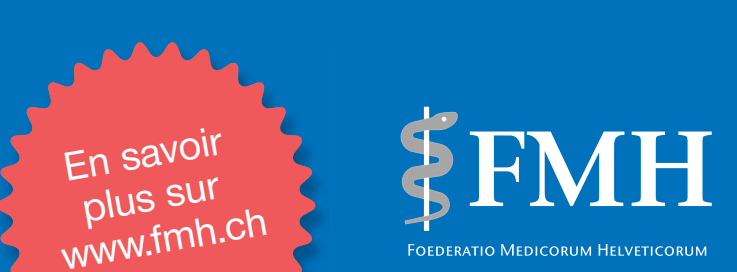

